\title{
The effect of farrowing duration and parity on preovulatory follicular size and oxytocin release of sows at subsequent oestrus
}

\author{
Yun, J.
}

2018-06

Yun , J , Bjorkman , S, Oliviero , C, Soede , N \& Peltoniemi , O 2018, ' The effect of farrowing duration and parity on preovulatory follicular size and oxytocin release of sows at subsequent oestrus ' , Reproduction in Domestic Animals , vol. 53 , no. 3 , pp. 776-783 . https://doi.org/10.1111/rda.

http://hdl.handle.net/10138/326481

https://doi.org/10.1111/rda.13170

unspecified

acceptedVersion

Downloaded from Helda, University of Helsinki institutional repository.

This is an electronic reprint of the original article.

This reprint may differ from the original in pagination and typographic detail.

Please cite the original version. 
1 The effect of farrowing duration and parity on preovulatory follicular size and oxytocin release of sows at subsequent oestrus - Effects of farrowing duration and parity at subsequent oestrus of sows

4

$5 \quad J_{i n h y e o n}$ Yun $^{\mathrm{a}, *}$, Stefan Björkman $^{\mathrm{b}, *}$, Claudio Oliviero $^{\mathrm{b}}$, Nicoline Soede $^{\mathrm{c}}$, Olli Peltoniemi $^{\mathrm{b}}$

$6 \quad$ anesearch Centre for Animal Welfare, Department of Production Animal Medicine, P.O. Box 57,

$7 \quad 00014$ University of Helsinki, Finland

8 bProduction Animal Hospital, Department of Production Animal Medicine, P.O. Box 66, 00014

$9 \quad$ University of Helsinki, Finland

$10{ }^{\mathrm{c} W U}$ Adaptation Physiology Group, Animal Sciences, P.O. Box 338, 6700AH Wageningen, The

11 Netherlands

*Joint first and corresponding author. Email: jinhyeon.yun@ helsinki.fi; stefan.bjorkman@helsinki.fi

Contents

This study examined the extent to which prolonged farrowing and parity are associated with plasma oxytocin concentrations and follicular development of oestrous sows during subsequent insemination.

17 A total of 30 sows were allocated to two groups based on farrowing duration: 1$)$ SHORT $(n=14): 159$ $\pm 29 \min , 2)$ LONG ( $=16): 533 \pm 190 \mathrm{~min}$. The sows were also divided into two parity classes: 1$)$

19 YOUNG $(n=14)$ : parity $2.5 \pm 0.8,2)$ OLD $(n=16)$ : parity $6.4 \pm 2.3$. After weaning, the ovaries were examined daily with transrectal ultrasound. On the second day of oestrus, blood samples were collected for oxytocin (OT) assay at $-15,-10,-5,0,+1,+2,+3,+4,+6,+8,+10,+15,+20,+25,+30,+40,+50$ 
and +60 min with a boar contact between 0 and +10 min. Boar presence stimulated an increase in OT concentrations $(P<0.05)$. During boar presence, OT in the LONG group were higher than in the SHORT group $(P<0.01)$. The sows in the OLD group had a longer farrowing duration than in the YOUNG group $(P<0.05)$. OT levels and diameters of follicles were more relevant for parity than was the duration of farrowing. We therefore conclude that the OT levels and follicular development of oestrous sows are associated due to parity but difficult to be predicted from the duration of previous farrowing.

Key words: sows, farrowing duration, oestrus, boar presence, standing reflex, insemination

\section{Introduction}

Prolonged farrowing was reported to be unfavourably associated with perinatal mortality (Borges et al., 2005; Fraser et al., 1997; Van Dijk et al., 2005), mainly by increasing the risk of hypoxia in piglets (Herpin et al., 1996). In addition to consequences for piglet vitality, prolonged farrowing also seems to be related to subsequent sow performance. A recent study showed that sows with prolonged farrowing had a reduced pregnancy rate after the subsequent post-weaning insemination (Oliviero et al., 2013). Causes of prolonged farrowing are reported to be large litter size (Borges et al., 2005; Herpin et al., 1996), high parity (Björkman et al., 2017; Oliviero et al., 2010), confined farrowing environment (Gu et al., 2011; Oliviero et al., 2008; Yun et al., 2015), and restricted prepartum maternal behaviour of sows (Pedersen et al., 2006), which are also shown to be associated with a decrease in oxytocin (OT) concentrations during parturition (Björkman et al., 2017; Oliviero et al.., 2008, 2010; Yun et al., 2015).

Sufficient myometrial activity is needed during farrowing for rapid expulsion of piglets and consequent prevention of prolonged farrowing (Castrén et al., 1993a; Jarvis et al., 2004; Lawrence et 
44

al., 1997; Oliviero et al., 2008). It is known that OT is one of the major modulators of uterine activity (Higuchi et al., 1985; Taverne et al., 1979). The OT baseline concentrations start to increase about 6 hours before parturition, peak after the birth of each piglet, and decrease thereafter (Castrén et al., 1993b; Gilbert et al., 2002; Oliviero et al., 2008; Yun et al., 2015). Previous evidences consequentially suggested that the reduced basal and peak OT concentrations have been associated with prolonged farrowing (Castrén et al., 1993a; Oliviero et al., 2008).

After weaning, the production and release of OT is stimulated by estradiol produced from follicles (Carter, 1992; Gimpl and Fahrenholz, 2001; Wathes et al., 1996) which is supported by increasing gonadotrophin stimulation, particularly by FSH and LH (Kemp et al., 2005; Van den Brand et al., 2000; Van Leeuwen et al., 2011). The positive relationship between follicular development and estradiol concentrations during the follicular phase was confirmed by several studies (Breuel et al., 1993; Nayudu et al., 1992; Sheldon and Dobson, 2004). However, to the best of our knowledge, there is little research to investigate the association between OT concentrations and follicular size of oestrous sows. OT release is triggered during oestrus by introduction of a boar to the sows (Langendijk, 2003, 2005), and it plays an important role in myometrial activity, and thereby in sperm transportation to the oviducts (Langendijk et al., 2005). Parity also affects myometrial activity at oestrus (Langendijk et al., 2005).

Therefore, the current study aimed to investigate the relationship between previous farrowing duration (FD) and OT levels of the subsequent oestrous sows, and to examine the interactions with size of preovulatory follicles. We also aimed to study the effect of parity on this relationship. We focused on plasma OT concentrations of the oestrous sows, and hypothesized that prolonged farrowing and high parity would be associated with lower OT concentrations of the sows during subsequent oestrus. We also hypothesized that the OT concentrations in oestrous sows would be positively associated with size of preovulatory follicles. 
Experimental procedures were reviewed and approved by the Animal Experiment Board (ELLA: ESAVI/3331/04.10.03/2011) in Finland.

\subsection{Animals and management}

Two single experiments were conducted on two different research herds in southern Finland. Herd 1: approximately 400 crossbred (Finnish Yorkshire $\times$ Landrace) sows were housed in peat-bedded pens $(8$ $\times 5 \mathrm{~m}$ ) in groups of 8-10 during pregnancy, and confined in farrowing and lactation pens, which consisted of a conventional steel farrowing crate on a fully-slatted plastic floor during parturition and lactation. Herd 2: approximately 280 crossbred (Finnish Yorkshire $\times$ Large White) sows were housed in groups, twenty per group pen $(20 \times 5 \mathrm{~m}$, straw-bedded $)$ during pregnancy, and confined in farrowing and lactation pens which consisted of a conventional steel farrowing crate on a half-slatted concrete floor during parturition and lactation. After a four week lactation period ( $27.0 \pm 1.8$ days), all sows included in the study were confined in stalls individually and catheterized two or three days after weaning through the auricular vein following a nonsurgical catheterization procedure (Yun et al.,

82 2017). Starting three days after weaning, standing oestrus of the sow was tested daily at 08:30 and 15:30 until detected by applying a back pressure test while the sows had nose-to-nose contact with a boar. For doing that, always the same boar was used in each herd.

\subsection{Experimental design}

A total of 30 crossbred sows [19 sows (FD 361.3 \pm 210.3 , parity $5.3 \pm 3.0$ ) in 4 batches for Herd 1, and 11 sows (FD 353.5 \pm 284.0 , parity $3.3 \pm 1.2$ ) in 3 batches for Herd 2] were selected for the study. 
$3.8 \pm 2.6$ ) with shorter than 200 min of FD (range $103-192 \mathrm{~min}$ ), and 2) LONG: 16 sows (parity $5.3 \pm$ 2.5 ) with FD between 300 and 900 min (range 326 - 878 min). The classification of FD in the present study was set based on the recent studies suggesting that prolonged farrowing was defined as longer than 300 min of FD (Oliviero et al., 2010, 2013). The sows included in the study were also divided into two age classifications: 1) YOUNG: 14 sows with parity between 1 and 3 (average $2.5 \pm 0.8$ ), and 2)

OLD: 16 sows with parity between 4 and 11 (average $6.4 \pm 2.3$ ). The parity group was classified based on the previous evidences showing that FD initiated to increase from the $4^{\text {th }}$ parity (Oliviero et al., 2010; Björkman et al., 2017). Sows requiring induced delivery or distinct parturition assistance by farm personnel were excluded from the study.

\subsection{Observation of farrowing duration}

The farrowings of the sows were video-recorded using internet protocol (IP) cameras (Niceview NICECAN420WL, Niceview Corp.). The cameras were placed behind and $1.5 \mathrm{~m}$ above the sows 2 days before expected farrowing date. The sequence output was recorded by IP-camera software (Blue Iris v.2.64, Perspective Software Corp.) and examined with a media player (Windows media player 12.0, Microsoft Corp.) by a trained observer. The display resolution was $640 \times 480$ pixels, and the frame rate was 2 FPS. FD was determined as time interval between the expulsion of the first and the last piglet.

\subsection{Blood collection and oxytocin assay during oestrus}

During blood collection, a boar was presented across the stall, and back, flank or both pressures were applied to the sow for $10 \mathrm{~min}$. When initiating sampling, the first $2 \mathrm{ml}$ of blood drawn was discarded, and the sample was taken using single-use vacuum needles into $3 \mathrm{ml}$ EDTA tubes adding 500kIU/ml of aprotinin for Herd 1 and $4 \mathrm{ml}$ EDTA tubes containing 500kIU/ml of aprotinin for Herd 2. Blood 
111 samples were collected $-15,-10,-5,0,+1,+2,+3,+4,+6,+8,+10,+15,+20,+25,+30,+40,+50$ and

$112+60$ minutes from the point of boar introduction. The boar was introduced to the sow for between 0 and $11310 \mathrm{~min}$.

114 OT concentrations for both trials were measured using an enzyme-linked immunosorbent assay kit 115 (Oxytocin ELISA kit, Enzo Life Sciences, Lausen, Switzerland). Purified plasma samples were 116 reconstituted with $250 \mu$ of assay buffer supplied in the ELISA kit, and analysed in duplicate 117 according to the assay kit instruction. Sensitivities of the plasma OT assays for Herds 1 and 2 were 7.8 $118 \mathrm{pg} / \mathrm{ml}$ and $3.9 \mathrm{pg} / \mathrm{ml}$, respectively. Average mass recovery was $89.6 \%$ and $90.1 \%$, and the intra- and 119 inter- assay CVs were $4.5 \%$ and $9.6 \%$, and $15.1 \%$ and $7.4 \%$, for $\mathrm{Herds} 1$ and 2 , respectively. the ovaries were performed twice a day at 09:00 and 15:00, starting three days after weaning until ovulation. Both ovaries were scanned at each examination. The clips were exported in DICOM format and analysed using the IMPAX 6.5.5 picture archiving and communication system (Agfa Healthcare, and averaged.

SAS v.9.4 (SAS Institute Inc., NC, USA, 2012) was used for statistical processing of all data. A nested design using a mixed model was used to compare LS means for FD, litter size, plasma OT concentrations and follicle development between FD class (SHORT and LONG), parity class (YOUNG and OLD) and their interactions. FD and parity classes were nested within the herds. Batch was used as a random effect. The experimental unit was the sow. 
Repeated measures using a mixed model were used to analyse periodical OT concentrations within

134 four periods relative to the onset of boar presence at $0 \mathrm{~min}: 1)-15,-10$ and -5 min (i.e. before boar presence), 2) 0, 1, 2, 3, 4, 6, 8 and 10 min (i.e. during boar presence), 3) 15, 20, 25, 30, 40, 50 and 60 min (i.e. after boar presence), and 4) total period. Interactions between FD and parity classes were analysed with multiple comparisons using the Tukey-Kramer procedure. Post hoc analyses using the Kenward-Rogers procedure were performed to compare the data for OT and follicle development between the treatments in YOUNG or in OLD groups separately. OT concentrations analysed by repeated measures during the total sampling period were used to determine correlations with FD, parity, and diameters of the follicles measured at five days after weaning and when they reached maximum size, using Spearman rank correlation coefficients $\left(r_{s}\right)$. Pearson correlation coefficients $(r)$ were applied to examine correlations of parity with average follicle diameters at five days after weaning and the days it took follicles to reach maximum diameter.

\subsection{Farrowing duration and litter size}

Average FD of all sows was $358( \pm 235) \mathrm{min}$, with $159( \pm 29) \mathrm{min}$ in SHORT and $533( \pm 190) \mathrm{min}$ in $\pm \mathrm{SE}: 265 \pm 60$ vs. $459 \pm 63 \min , P<0.05)$. SHORT group $(14.3 \pm 1.2$ vs. $11.5 \pm 1.2, P=0.09)$. However, the number of total piglets born per litter did not differ between the OLD and YOUNG group $(12.9 \pm 1.1$ and $12.9 \pm 1.2$, respectively) 
Boar presence for 10 min brought about an increase in plasma OT concentrations of oestrous sows

156

157 compared with absence $(P<0.05$, Fig 1 , Table 1$)$. During boar presence, OT concentrations in the LONG group were higher than those in the SHORT group (LS means \pm SE; $27.8 \pm 5.5$ vs. $21.4 \pm 5.4, P$ $<0.01$, Table 1). OT concentrations were not correlated with FD, but were positively correlated with parity over the total period $\left(r_{s}=0.31, P<0.0001\right)$. Parity class (YOUNG vs. OLD) per se did not affect the OT levels during all sampling periods (Table 1), but sows in the YOUNG group with short FD tended to have the lowest OT levels post boar presence $(P=0.07$, Fig 1 , Table 1$)$. Among YOUNG group, the OT levels were higher in LONG than in SHORT during and post boar presence $(P<0.001$ and $P<0.01$, respectively), whereas in the OLD group, those were not affected by FD in all sampling periods (Table 1).

\subsection{Follicle development of oestrous sows}

FD and parity of the sow did not affect days of weaning-to-oestrus interval and when the five largest preovulatory follicles reached their maximum size between three days after weaning and ovulation (Table 2).

Mean diameters of the five largest follicles of the LONG sows tended to be larger than those of SHORT sows four days after weaning $(P=0.06)$, but did not differ on other days (Table 2). Diameters of the follicles of sows in the OLD group tended to be larger five days after weaning, or were larger when follicles reached their maximum size after weaning until ovulation compared with those of sows in the YOUNG group $(P=0.07, P=0.02$, respectively, Table 2$)$.

The mean diameters of the five largest follicles measured at five days after weaning and when the follicles reached their maximum size after weaning were weakly correlated with OT concentrations of the oestrous sows during the total period $\left(r_{s}=0.23, P<0.0001\right.$ and $r_{s}=0.38, P<0.0001$, respectively, 
177 Fig 2), and these were also even more moderately correlated with parity of the sow $(r=0.61, P<0.01$ 178 and $r=0.57, P<0.01$, respectively, Fig 3).

4. Discussion

Average FD in the current study was relatively short compared with that reported by Björkman et al. (2017) from our research station (358 vs. $411 \mathrm{~min}$ ). This might be related to the relatively low average number of total piglets born in the present experiment (13.4 vs. 16.3 piglets/litter), since large litter size was associated with prolonged farrowing (Fraser et al., 1997; Herpin et al., 1996; Van Rens and Van der Lende, 2004).

Van Dijk et al., 2005). In contrast, the results of the present study are in accordance with others demonstrating that FD increases as sows get older (Björkman et al., 2017; Borges et al., 2005; Cronin

et al., 1993; Pejsak, 1984). This association between higher parity and longer FD has been suggested to 190 be due to large litter size (Borges et al., 2005; Dial et al., 1992), higher body condition score (Oliviero et al., 2008), or/and degradation of myometrial activity (Pejsak, 1984). In the current study, however, we did not establish a relationship between parity per se and litter size. In addition, body frames and myometrial activity of sows were not measured in the present study. Therefore, no conclusion on the cause of the association between higher parity and longer FD in the current study can be drawn. during parturition in sows (Castrén et al., 1993b; Jarvis et al., 2004; Lawrence et al., 1997; Oliviero et al., 2008). It was determined that considerable pain and distress during the parturition period was even increased by prolonged farrowing (Mainau and Manteca, 2011; Rutherford et al., 2013), which in turn 
inhibited OT secretion in sows (Carter, 1992; Lawrence et al., 1997; Rutherford et al., 2013). We therefore considered that this association would result in reduced plasma OT concentrations of the sows during subsequent insemination. In contrast to one hypothesis, however, we found that prolonged

202 farrowing was associated with higher OT concentrations of the subsequent oestrous sows in the YOUNG group when standing reflex was triggered by boar introduction. that OT concentrations of oestrous sows peak in response to boar introduction. In the current study, the back and flank of the sows were stimulated by samplers while the sows had nose-to-nose contact with a boar. Langendijk et al. (2005), however, suggested that stimulation of the back and flank of sows without boar introduction may not affect the release of OT, while Mattioli et al. (1986) reported that olfactory stimulation could lead to an increase in OT concentrations of sows at insemination. Therefore, it can be speculated that our findings indicate that boar odour, potentially accompanied by presence of a boar, may make a greater contribution to elevating OT concentrations than sole stimulation of the back and flank of oestrous sows during the insemination period. Follicular development in the present study could represent another explanation for the relationship between prolonged farrowing and increased OT concentrations and their interactions with parity in oestrous sows. The present results indicate that tendencies for larger follicles, seen in the LONG group and in the OLD group on day four or five after weaning respectively, could have originated from higher

217 OT concentrations of the oestrous sows. It is suggested that the production and the release of OT is stimulated by oestrogen (Gimpl and Fahrenholz, 2001; Wathes et al., 1996) which can be produced from follicles (Carter, 1992). Furthermore, levels of oestrogen were positively correlated with density of OT receptors in the myometrium (Hoang-Vu, 1987; Okano and Okuda, 1996). It can therefore be 
221 speculated that the larger follicles in older sows and in sows with prolonged farrowing may produce

222 more estradiol, which in turn could influence an increase in OT concentration.

223 The size of the largest follicles of the oestrous sows measured in the present study was estimated to be

224

225

226

227

similar to the size of ovulated follicles. The current results may support the previous findings of Langendijk et al. (2000) and Gerritsen et al. (2008) confirming that primiparous sows had smaller follicles than multiparous sows at weaning (on average $2.5 \mathrm{vs.} 3.3 \mathrm{~mm}$ ), and ovulation (on average 7 vs. $8 \mathrm{~mm}$ ). The effects of parity on follicular development and endocrine profiles after weaning could be due to the negative energy balance caused by lactation weight loss (Soede et al., 2011; Soede and Kemp, 2015). Younger sows appeared more sensitive to lactation weight loss than older sows (Hoving et al., 2011; Thaker and Bilkei, 2005). Clowes et al. (2003) also demonstrated the negative effects of body protein loss during lactation on follicular size, follicular fluid and estradiol-17 $\beta$ after weaning. Therefore, the smaller size of the maximal follicles seen in the YOUNG sows in the present study is presumably linked to sow metabolism during lactation. However, further studies are needed to investigate the causal relationship between metabolic status during lactation and follicular development after weaning.

\section{Conclusions}

Contrary to an expectation of the present study, there was a positive association between farrowing duration and oxytocin concentrations at subsequent oestrus among YOUNG sows. On the other hand, we found that both farrowing duration and the oxytocin levels at oestrus increased as sows got older. In addition, our results suggest that the positive associations between the oxytocin levels and diameters of the follicles at oestrus were also originated from parity. Therefore, we conclude that plasma oxytocin 
243 concentrations and follicular development of oestrous sows are associated due to parity but difficult to

244 be predicted from the duration of previous farrowing.

246 Acknowledgements

247 This study was funded by the Finnish Ministry of Agriculture (MMM, grant no: 2017/312/2011),

248 Mercedes-Zacharias Research Foundation, Hankkija, Vetcare, Figen, Atria and Finnish Foundation of

249 Veterinary Research. The authors thank Merja Pöytäkangas (lab technician) for help with the oxytocin 250 analyses.

251

252 Conflict of interest statement

253 None.

254

255 References

256 Björkman, S., Oliviero, C., Rajala-Schultz, P., Soede, N., and Peltoniemi, O. (2017). The effect of litter 257 size, parity and farrowing duration on placenta expulsion and retention in sows. Theriogenology 92, 3625844.

259 Borges, V., Bernardi, M., Bortolozzo, F., and Wentz, I. (2005). Risk factors for stillbirth and foetal 260 mummification in four Brazilian swine herds. Preventive Veterinary Medicine. 70, 165-176. 
261 Breuel, K., Lewis, P., Schrick, F., Lishman, A., Inskeep, E., and Butcher, R.. (1993). Factors affecting

262 fertility in the postpartum cow: role of the oocyte and follicle in conception rate. Biology of

263 Reproduction, 48, 655-661.

264 Carter, C. (1992). Oxytocin and sexual behavior. Neuroscience and Biobehavioral Reviews, 16, 131265144.

266 Castrén, H., Algers, B., De Passillé, A., Rushen, J., and Uvnäs-Moberg, K. (1993a). Early milk 267 ejection, prolonged parturition and periparturient oxytocin release in the pig. Animal Science, 57, 465268471.

269 Castrén, H., Algers, B., De Passille, A., Rushen, J., and Uvnäs-Moberg, K. (1993b). Preparturient 270 variation in progesterone, prolactin, oxytocin and somatostatin in relation to nest building in sows. 271 Applied Animal Behaviour Science, 38, 91-102.

272 Clowes, E., Aherne, F., Foxcroft, G., and Baracos, V. (2003). Selective protein loss in lactating sows is 273 associated with reduced litter growth and ovarian function. Journal of Animal Science, 81, 753-764.

274 Cronin, G., Schirmer, B., McCallum, T., Smith, J., and Butler, K. (1993). The effects of providing 275 sawdust to pre-parturient sows in farrowing crates on sow behaviour, the duration of parturition and the 276 occurrence of intra-partum stillborn piglets. Applied Animal Behaviour Science, 36, 301-315.

277 Dial, G., Marsh, W., Polson, D., and Vaillancourt, J. (1992). Reproductive failure: differential 278 diagnosis. Diseases of swine 7, 88-137.

279 Fahmy, M., and Friend, D. (1981). Factors influencing, and repeatability of the duration of farrowing in 280 Yorkshire sows. Canadian Journal of Animal Science, 61, 17-22. 
281 Fraser, D., Phillips, P. and Thompson, B. (1997). Farrowing behaviour and stillbirth in two

282 environments: an evaluation of the restraint-stillbirth hypothesis. Applied Animal Behaviour Science, $28355,51-66$.

284 Gerritsen, R., Soede, N., Langendijk, P., Dieleman, S., Hazeleger, W., and Kemp, B. (2008). Peri285 oestrus Hormone Profiles and Follicle Growth in Lactating Sows with Oestrus Induced by Intermittent 286 Suckling. Reproduction in Domestic Animals, 43, 1-8.

287 Gilbert, C., Burne, T., Goode, J., Murfitt, P., and Walton, S. (2002). Indomethacin blocks pre-partum 288 nest building behaviour in the pig (Sus scrofa): effects on plasma prostaglandin F metabolite, oxytocin, 289 cortisol and progesterone. Journal of Endocrinology, 172, 507-517.

290 Gimpl, G., and Fahrenholz, F. (2001). The oxytocin receptor system: structure, function, and 291 regulation. Physiological reviews, 81, 629-683.

292 Gu, Z., Gao, Y., Lin, B., Zhong, Z., Liu, Z., Wang, C., and Li, B. (2011). Impacts of a freedom 293 farrowing pen design on sow behaviours and performance. Preventive Veterinary Medicine, 102, 296294303.

295 Herpin, P., Le Dividich, J., Hulin, J., Fillaut, M., De Marco, F., and Bertin, R. (1996). Effects of the 296 level of asphyxia during delivery on viability at birth and early postnatal vitality of newborn pigs. 297 Journal of Animal Science, 74, 2067-2075.

298 Higuchi, T., Honda, K., Fukuoka, T., Negoro, H., and Wakabayashi, K. (1985). Release of oxytocin 299 during suckling and parturition in the rat. Journal of Endocrinology, 105, 339-346.

Hoang-Vu, C. (1987). Elektrische Aktivität des Myometriums beim Schwein während des Zyklus und 301 ihre Beeinflussung durch Infusion von Östrogenen in das Uteruslumen am Tag der Rausche. Thesis, 302 Hohenheim University (Germany). 
Hoving, L., Soede, N., Graat, E., Feitsma, H., and Kemp, B. (2011). Reproductive performance of second parity sows: Relations with subsequent reproduction. Livestock Science. 140, 124-130.

Jarvis, S., Reed, B., Lawrence, A., Calvert, S., and Stevenson, J. (2004). Peri-natal environmental effects on maternal behaviour, pituitary and adrenal activation, and the progress of parturition in the 307 primiparous sow. Animal Welfare, 13, 171-181.

Kemp, B., Soede, N., and Langendijk, P. (2005). Effects of boar contact and housing conditions on estrus expression in sows. Theriogenology, 63, 643-656. follicular development and on estrus expression after weaning in primiparous sows. Theriogenology, 54, 1295-1303.

Langendijk, P., Bouwman, E., Schams, D., Soede, N., and Kemp, B. (2003). Effects of different sexual stimuli on oxytocin release, uterine activity and receptive behavior in estrous sows. Theriogenology, 59, 849-861. stimuli around insemination in sows. Theriogenology, 63, 500-513. pig. Reproduction in Domestic Animals, 32, 231-236.

Mainau, E., and Manteca, X. (2011). Pain and discomfort caused by parturition in cows and sows. Applied Animal Behaviour Science, 135, 241-251.

322 Mattioli, M., Galeati, G., Conte, F., and Seren, E. (1986). Effect of 5 $\alpha$-androst-16-en-3-one on oxytocin 323 release in oestrous sows. Theriogenology 25, 399-403. 
324 Nayudu, P., and Osborn, S. (1992). Factors influencing the rate of preantral and antral growth of mouse 325 ovarian follicles in vitro. Journal of Reproduction and Fertility, 95, 349-362.

326 Okano, A. and Okuda, K. (1996). Oxytocin receptors in the porcine myometrium during the estrous 327 cycle and early pregnancy. Nihon Chikusan Gakkaiho 67, 102-103.

Oliviero, C., Heinonen, M., Valros, A., Hälli, O., and Peltoniemi, O. (2008). Effect of the environment 329 on the physiology of the sow during late pregnancy, farrowing and early lactation. Animal Reproduction Science, 105, 365-377.

Oliviero, C., Heinonen, M., Valros, A., and Peltoniemi, O. (2010). Environmental and sow-related 332 factors affecting the duration of farrowing. Animal Reproduction Science, 119, 85-91. farrowing is associated with subsequent decreased fertility in sows. Theriogenology, 79, 1095-1099.

Pedersen, L., Jørgensen, E., Heiskanen, T., and Damm, B. (2006). Early piglet mortality in loosehoused sows related to sow and piglet behaviour and to the progress of parturition. Applied Animal Behaviour Science, 96, 215-232.

Pejsak, Z. (1984). Some pharmacological methods to reduce intrapartum death of piglets. Pig News and Information.

340 Rutherford, K., Baxter, E., D'Eath, R., Turner, S., Arnott, G., Roehe, R., Ask, B., Sandoe, P. Moustsen, 341 V., Thorup, F., and Edwards, S. (2013). The welfare implications of large litter size in the domestic pig 342 I: biological factors. Animal Welfare, 22, 199-218.

343 Sheldon, I., and Dobson, H. (2004). Postpartum uterine health in cattle. Animal Reproduction Science, $34482,295-306$. 
345 Soede, N., Langendijk, P., and Kemp, B. (2011). Reproductive cycles in pigs. Animal Reproduction 346 Science, 124, 251-258.

347 Soede, N., and Kemp, B. (2015). Best practices in the lactating and weaned sow to optimize

348 reproductive physiology and performance. In The gestating and lactating sow. pp. 99-106. (Press:

349 Wageningen Academic Publishers).

350 Taverne, M., Naaktgeboren, C., Elsaesser, F., Forsling, M., Van der Weyden, G., Ellendorff, F., and

351 Smidt, D. (1979). Myometrial electrical activity and plasma concentrations of progesterone, estrogens

352 and oxytocin during late pregnancy and parturition in the miniature pig. Biology of Reproduction, 21, $353 \quad 1125-1134$.

354 Thaker, M., and Bilkei, G. (2005). Lactation weight loss influences subsequent reproductive 355 performance of sows. Animal Reproduction Science, 88, 309-318.

356 Van den Brand, H., Dieleman, S., Soede, N., and Kemp, B. (2000). Dietary energy source at two 357 feeding levels during lactation of primiparous sows: I. Effects on glucose, insulin, and luteinizing 358 hormone and on follicle development, weaning-to-estrus interval, and ovulation rate. Journal of Animal 359 Science, 78, 396-404.

360 Van Dijk, A., Van Rens, B., Van der Lende, T., and Taverne, M. (2005). Factors affecting duration of 361 the expulsive stage of parturition and piglet birth intervals in sows with uncomplicated, spontaneous 362 farrowings. Theriogenology, 64, 1573-1590.

363 Van Leeuwen, J., Williams, S., Martens, M., Jourquin, J., Driancourt, M., Kemp, B., and Soede, N. 364 (2011). The effect of different postweaning altrenogest treatments of primiparous sows on follicular 365 development, pregnancy rates, and litter sizes. Journal of Animal Science, 89, 397-403. 
366 Van Rens, B., and Van der Lende, T. (2004). Parturition in gilts: duration of farrowing, birth intervals

367 and placenta expulsion in relation to maternal, piglet and placental traits. Theriogenology, 62, 331-352.

368 Wathes, D., Mann, G., Payne, J., Riley, P., Stevenson, K., and Lamming, G. (1996). Regulation of 369 oxytocin, oestradiol and progesterone receptor concentrations in different uterine regions by oestradiol, 370 progesterone and oxytocin in ovariectomized ewes. Journal of Endocrinology, 151, 375-393.

371 Yun, J., Swan, K., Oliviero, C., Peltoniemi, O., and Valros, A. (2015). Effects of prepartum housing 372 environment on abnormal behaviour, the farrowing process, and interactions with circulating oxytocin 373 in sows. Applied Animal Behaviour Science, 162, 20-25.

374 Yun, J., Björkman, S., Pöytäkangas, M., and Peltoniemi, O. (2017). The effects of ovarian biopsy and 375 blood sampling methods on salivary cortisol and behaviour in sows. Research in Veterinary Science, $376114,80-85$.

377 
378 Table 1. The effects of farrowing duration and parity on the plasma oxytocin concentrations of sows 379 during post-weaning oestrus in presence of a boar ${ }^{\dagger}$.

\begin{tabular}{|c|c|c|c|c|c|c|c|}
\hline \multirow{3}{*}{ Period ${ }^{\ddagger}$} & \multicolumn{2}{|c|}{ YOUNG } & \multicolumn{2}{|c|}{ OLD } & \multicolumn{3}{|c|}{$P$ value } \\
\hline & & & & & $F D^{\S}$ & Parity ${ }^{\mathbb{I I}}$ & $F D^{*}$ parity \\
\hline & $(n=9)$ & $(\mathrm{n}=5)$ & $(n=5)$ & $(\mathrm{n}=11)$ & & & \\
\hline-15 to $-5 \mathrm{~min}$ & $13.8 \pm 1.5$ & $14.8 \pm 1.7$ & $13.7 \pm 1.7$ & $13.3 \pm 1.6$ & 0.79 & 0.76 & 0.48 \\
\hline 0 to $10 \mathrm{~min}$ & $18.6 \pm 7.6$ & $28.9 \pm 7.8$ & $24.2 \pm 7.8$ & $27.6 \pm 7.7$ & $<0.01$ & 0.84 & 0.13 \\
\hline 15 to $60 \mathrm{~min}$ & $13.7 \pm 2.5$ & $16.8 \pm 2.6$ & $16.6 \pm 2.7$ & $16.2 \pm 2.6$ & 0.58 & 0.79 & 0.07 \\
\hline-15 to $60 \mathrm{~min}$ & $16.9 \pm 2.5^{\mathrm{b}}$ & $19.7 \pm 2.6^{\mathrm{a}}$ & $18.8 \pm 2.6^{\mathrm{ab}}$ & $18.8 \pm 2.5^{\mathrm{ab}}$ & 0.44 & 0.91 & 0.04 \\
\hline
\end{tabular}

$\bar{\dagger}$ Values represent LS means \pm SEM of plasma oxytocin concentrations of the sows (total $\mathrm{n}=30$ ).

$381 \ddagger$ Repeated measures carried out on the values over four periods: 1) -15, -10 and -5 min before boar 382 presence, 2) 0, 1, 2, 3, 4, 6, 8 and 10 min during 10 min of boar presence, 3) 15, 20, 25, 30, 40, 50 and 38360 min after boar presence, and 4) total period.

$384{ }^{\S} \mathrm{FD}$ (farrowing duration) was divided into two classes: 1) SHORT: between 103 and 192 min, and 2) 385 LONG: between 326 and $878 \mathrm{~min}$.

386 TParity was divided into two classes: 1) YOUNG: between 1 and 3, and 2) OLD: between 4 and 11.

${ }^{\mathrm{a}, \mathrm{b}}$ Different letters indicate that variables were significantly different at $P<0.05$. 
389 Table 2. The effects of farrowing duration and parity on follicular development and weaning to oestrus 390 intervals of subsequent oestrous sows.

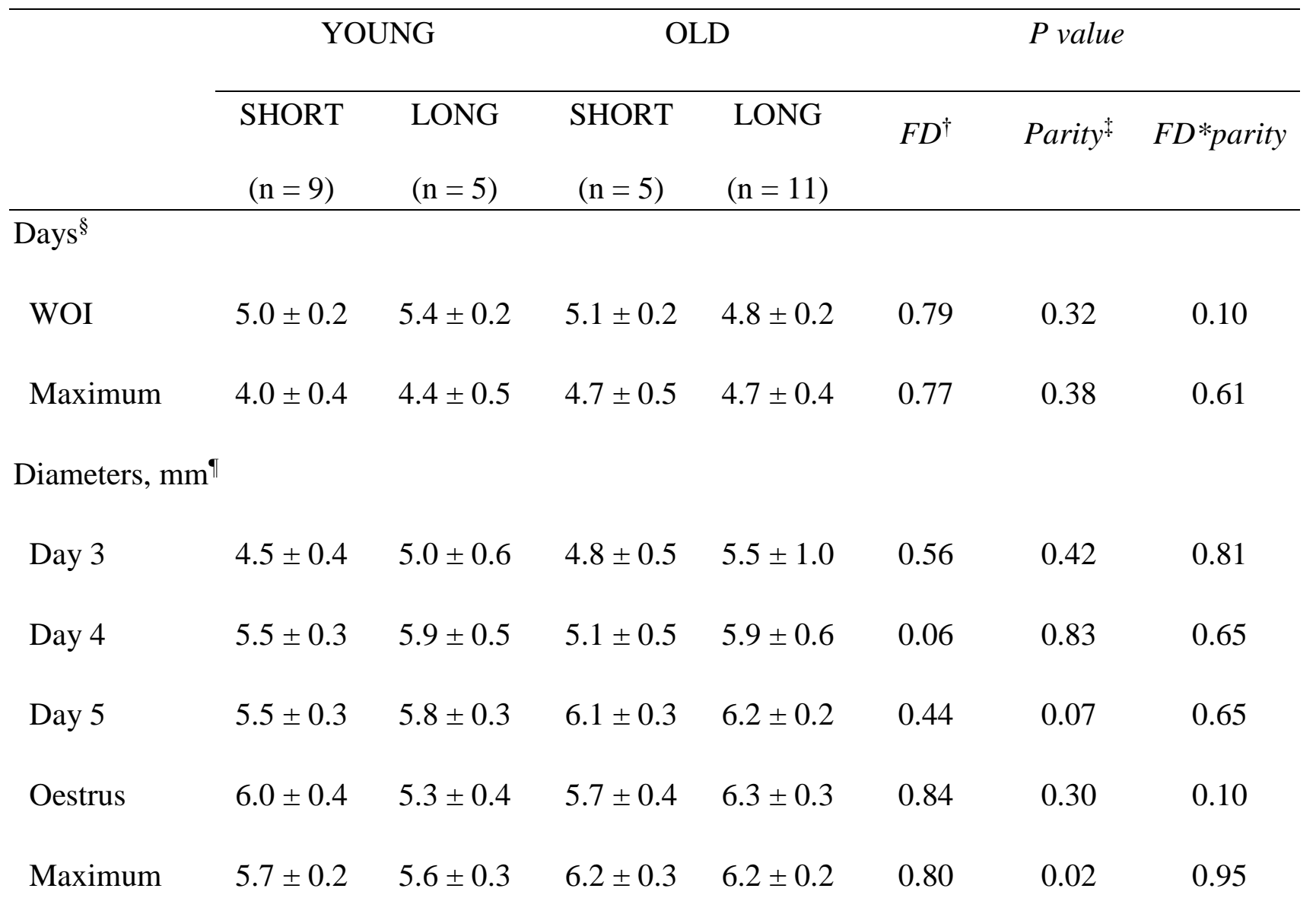

$\bar{\dagger}$ FD (farrowing duration) was divided into two groups: 1) SHORT: between 103 and 192 min, and 2)

392 LONG: between 326 and $878 \mathrm{~min}$.

$393{ }^{2}$ Parity was divided into two groups: 1) YOUNG: between 1 and 3, and 2) OLD: between 4 and 11.

$394 \S$ Values represent LS means \pm SE of the days for 1) weaning-to-oestrus interval, and 2) when the 5 395 largest follicles reached their maximum size after weaning until ovulation.

396 IValues represent LS means \pm SE of the mean diameters of the five largest follicles measured 1) on day 3973,2 ) on day 4 and 3) on day 5 after weaning until ovulation, 4) at oestrus in which the sow showed a 
398 standing response to the back test, and 5) when the follicles reached their maximum size after weaning 399 until ovulation. 


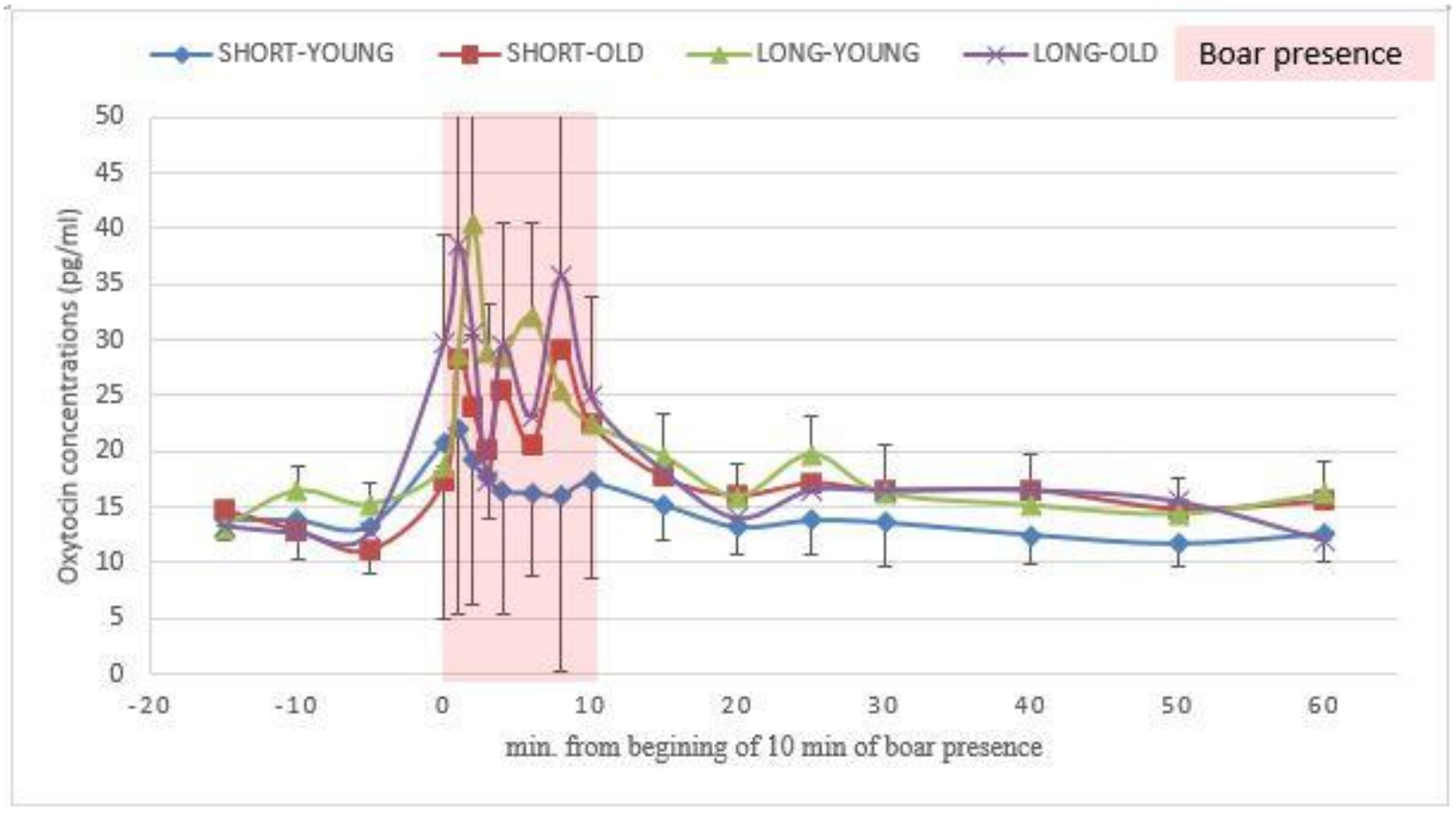

402 Figure 1. Plasma OT concentrations (LS means and SE) of oestrous sows in boar presence are plotted 403 by SHORT-YOUNG $(n=9)$, SHORT-OLD $(n=5)$, LONG-YOUNG $(n=5)$ and LONG-OLD $(n=11)$

404 groups, according to farrowing duration and parity classes. The red shading indicates 10 min of boar 405 presence.

406 

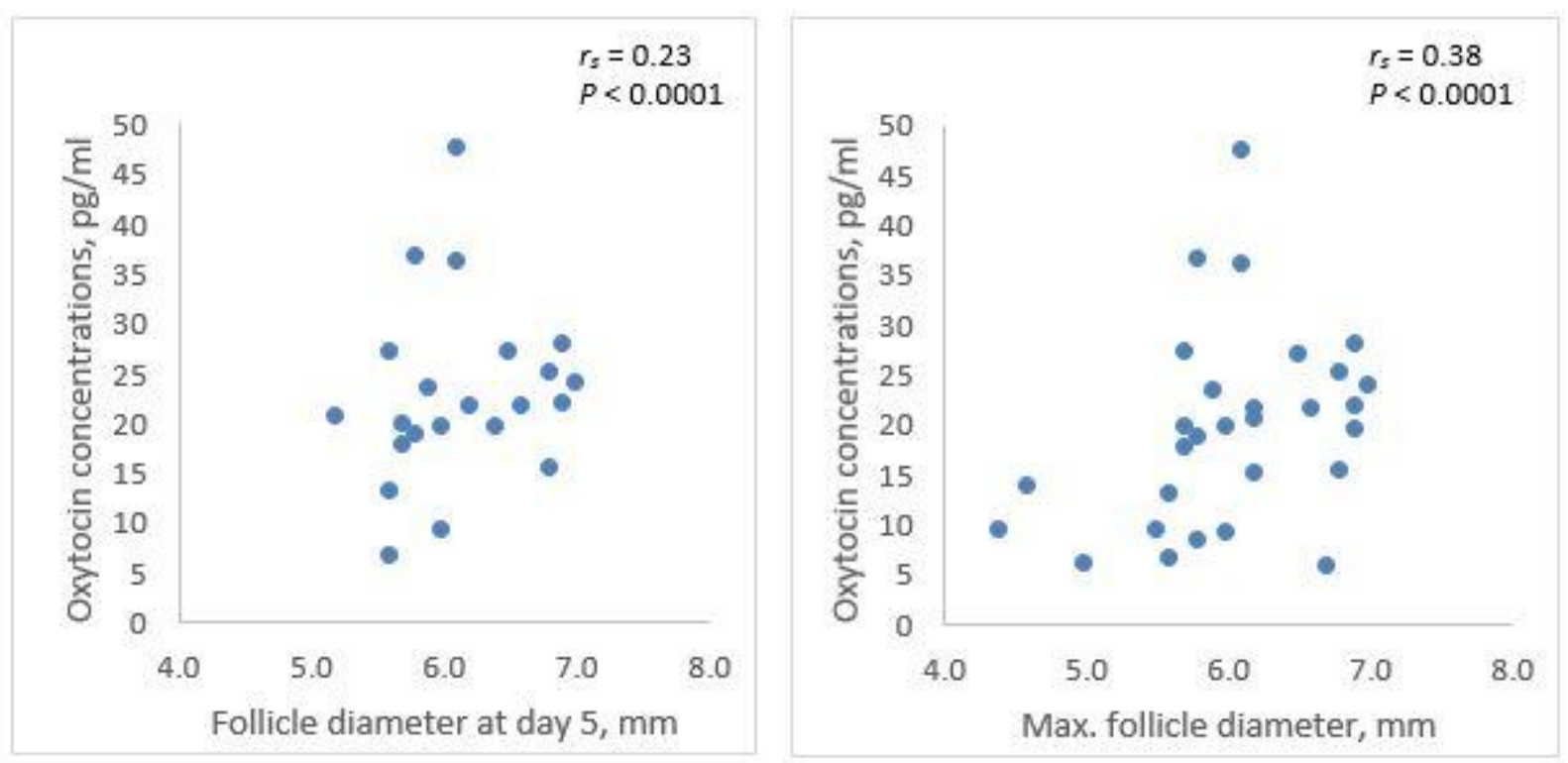

408 Figure 2. Average plasma oxytocin concentrations of the sows during the total sampling period, i.e. 40915 to $+60 \mathrm{~min}$ from beginning of $10 \mathrm{~min}$ of boar presence, and follicle diameters measured at five days 410 after weaning and when the follicles reached their maximum size after weaning until ovulation are 411 indicated with Spearman correlation coefficients $\left(r_{s}\right)(\mathrm{n}=30)$. Correlations were determined by 412 repeated measures. 

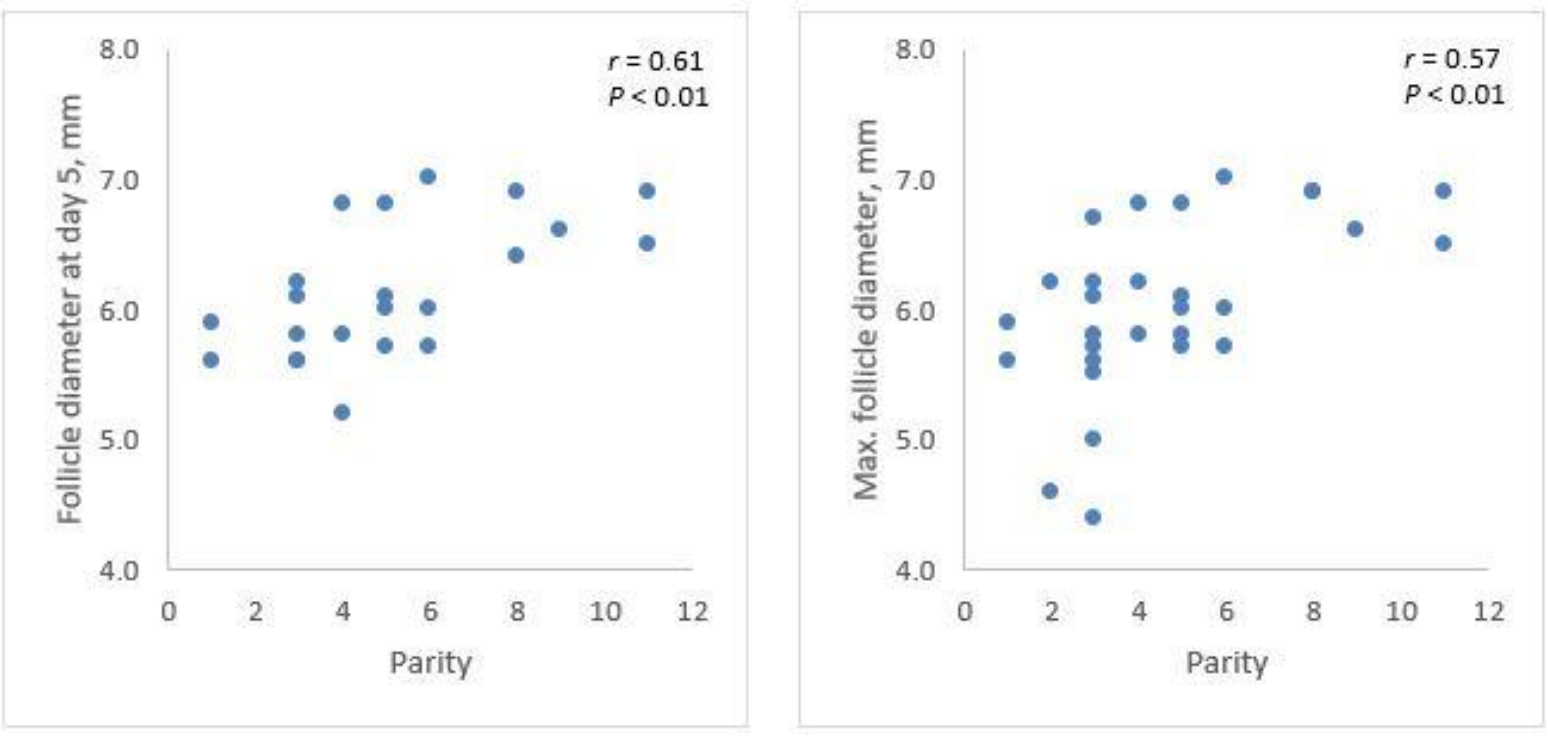

415 Figure 3. Parity of the sows and follicle diameters measured at five days after weaning and when the

416 follicles reached their maximum size after weaning until ovulation are indicated with Pearson

417 correlation coefficients $(r)(\mathrm{n}=30)$.

418 